\title{
CARCINOMA TRANSICIONAL Y PRIAPISMO METASTÁTICO
}

\author{
M.A. TRÍVEZ BONED, J.M. ARANDA LASSA, J. LOZANO ENGUITA, \\ C. AMBROJ NAVARRO, C. CEBRIÁN*
}

Sección de Urología. *Servicio de Anatomía Patológica. Hospital Ernest Lluch. Calatayud. Zaragoza.

Actas Urol Esp. 28 (9): 694-697, 2004

\section{RESUMEN}

CARCINOMA TRANSICIONAL Y PRIAPISMO METASTÁSICO

El priapismo metastático es una rara entidad clínica que suele ser secundaria a tumores del aparato genitourinario y que se asocia a un mal pronóstico debido a que su presencia suele indicar diseminación metastática multiorgánica.

Presentamos un caso de priapismo secundario a metástasis peneana por carcinoma transicional y realizamos una revisión de la literatura médica.

PALABRAS CLAVE: Priapismo maligno. Metástasis.

\section{ABSTRACT \\ TRANSITIONAL CARCINOMA AND MALIGNANT PRIAPISM}

Malignant priapism is rare and usually secondary to genitourinary tumors. The prognosis is poor since it generally indicates the presence of multiorgan metastasis.

A case of malignant priapism or priapism secondary to penile metastasis from transitional carcinoma is presented and the literature is reviewed.

KEY WORDS: Malignant priapism. Penile metastasis. Transitional carcinoma.

$\mathrm{S}^{\mathrm{s}}$ considera Priapismo Metastático a la erección prolongada secundaria bien a la obstrucción del flujo venoso peneano o bien a la ocupación de los cuerpos cavernosos por parte de una neoplasia metastática ${ }^{1}$. Se trata de una entidad clínica muy poco frecuente que aparece en el 30-40\% de los casos de metástasis peneanas. El $75 \%$ de las metástasis peneanas corresponden a tumores primarios originarios del sistema génito-urinario ${ }^{1}$, siendo los más frecuentes los de próstata y vejiga seguidos de los de riñón y rectosigma ${ }^{2}$. Otras localizaciones menos frecuentes como testículo, páncreas, hígado, estómago, pulmón, nasofaringe, condrosarcoma mandibular así como melanoma maligno y linfoma de Burkitt se han descrito en la literatura ${ }^{3}$. El tipo celular pre- dominante es el carcinoma seguido del sarcoma, linfoma y tumores de etiología desconoci$\mathrm{da}^{4}$. Anatomopatológicamente los carcinomas más frecuentes son los adenocarcinomas prostáticos y renales, y el carcinoma de células transicionales de vejiga. Con menos frecuencia se han descrito sarcomas y linfomas.

\section{CASO CLÍNICO}

Se trata de un varón de 79 años sometido hace 5 años a Resección Transuretral de un carcinoma transicional vesical (T1GI). Acudió a nuestra consulta presentando un cuadro de induración dolorosa, generalizada de ambos cuerpos cavernosos de varias semanas de evolución, así como dolor óseo a nivel de la articulación sacro iliaca derecha. 
A la exploración peneana se apreciaba una induración de ambos cuerpos cavernosos en toda su longitud, que se hallaban erectos. Al tacto rectal la próstata no era sospechosa de malignidad (grado II).

En la analítica sanguínea todos los parámetros fueron normales, destacando un antígeno prostático específico de $1,68 \mathrm{ng} / \mathrm{ml}$.

La ecografía de aparato genitourinario descartó la presencia de recidiva tumoral a nivel vesical, sin apreciar ningún otro hallazgo patológico. En el mismo acto se realizó un Eco-doppler peneano en el que no se evidenciaron placas calcificadas (compatibles con enfermedad de La Peyronie). Apreciándose un flujo peneano normal.

Mediante la TAC abdominopélvica se descartó la existencia de afectación hepática y de adenomegalias a nivel retroperitoneal, iliacas ni inguinales. A nivel vesical y prostático no se apreciaron alteraciones radiológicas y los cuerpos cavernosos no presentaban signos de infiltración (Fig. 1).

Para completar el estudio de diseminación se realizó una Gammagrafía ósea (MDP Tc 99m) en la que se observaron imágenes compatibles con metástasis óseas en hemipelvis izquierda, pubis y sacro (Fig. 2).

Tras el estudio realizado y con la sospecha de afectación neoplásica de los cuerpos cavernosos realizamos una uretrocistoscópia, apreciándose una ocupación de la luz de la uretra peneana por múltiples lesiones papilares de aspecto superficial.

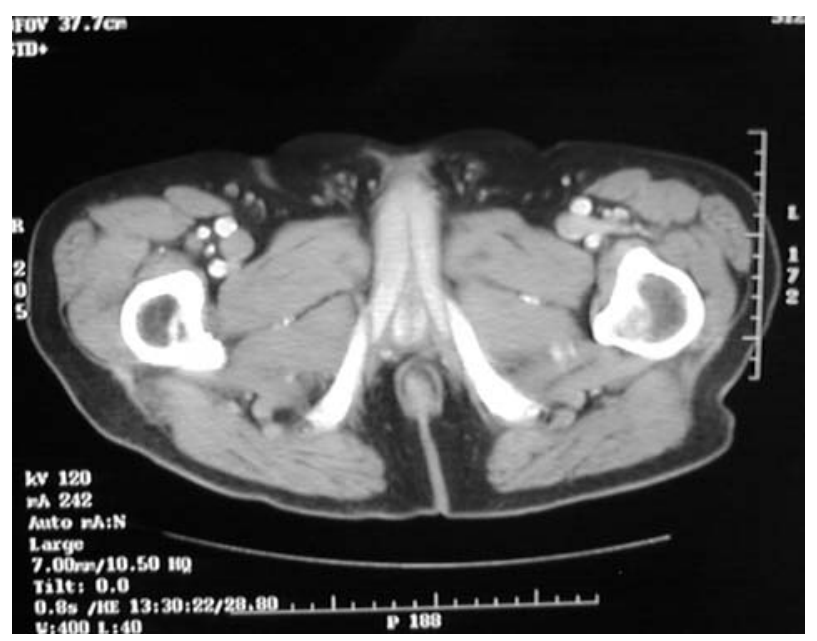

FIGURA 1. TAC abdominopélvica realizada como estudio de diseminación. Los cuerpos cavernosos no presentan signos de infiltración.

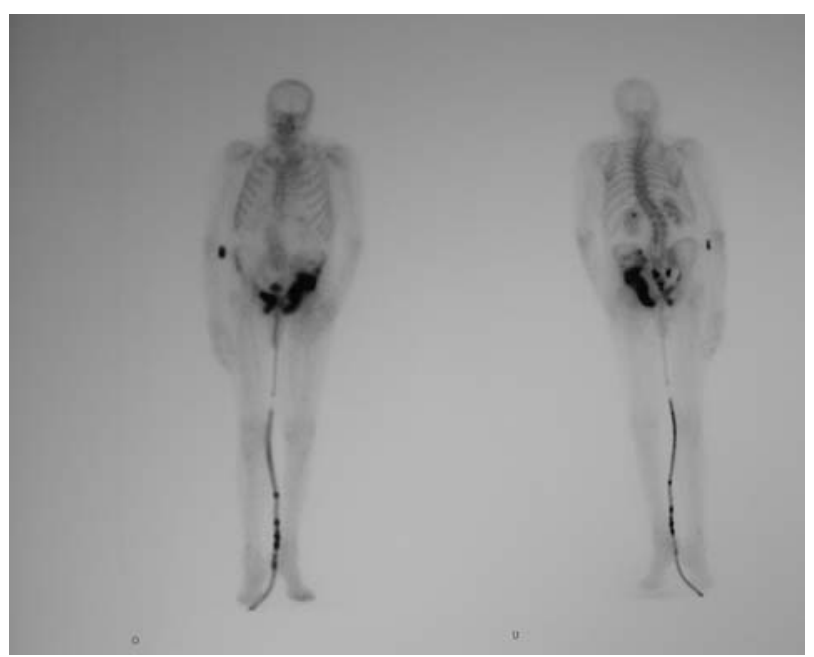

FIGURA 2. Gammagrafía ósea (MDP Tc 99m) mediante la cual confirmamos la existencia de metástasis óseas en hemipelvis izquierda, pubis y sacro.

A nivel vesical no existía recidiva neoplásica. Realizamos en el mismo acto una biopsia con pinza fría de las lesiones uretrales y biopsia percutánea con aguja (Microvasive $® 18$ GA.) de ambos cuerpos cavernosos.

El estudio anatomopatológico confirmo el diagnóstico de carcinoma transicional uretral de crecimiento papilar e invertido, bien-moderadamente diferenciado e infiltración del tejido conectivo subepitelial (T1 G1-2) (Fig. 3) con infiltración tumoral de ambos cuerpos cavernosos (Fig. 4).

La actitud terapéutica, dado que en el momento del diagnóstico ya existía diseminación metastática a otros órganos ha sido paliativa mediante tratamiento analgésico y complementos nutricionales.

Durante la evolución el paciente sufrió una retención urinaria aguda secundaria a compresión de la uretra peneana, siendo actualmente portador de sonda vesical permanente. Tras seis meses del diagnóstico el paciente mantiene una tumescencia peneana levemente dolorosa, presentando un severo deterioro de su estado general así como dolor óseo generalizado que requiere analgesia con opiáceos a dosis elevadas.

\section{DISCUSIÓN}

El priapismo metastático es una entidad clinica muy infrecuente. La afectación metastática sincrónica de otros órganos se produce en el 20\% de los casos, mientras que el 50\% se manifiesta a 


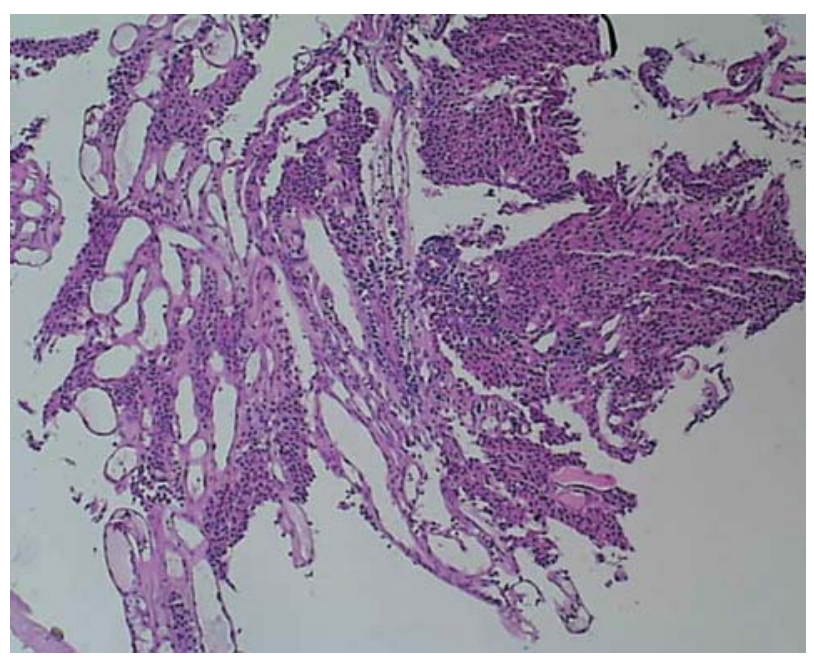

FIGURA 3. Uretra revestida con carcinoma transicional de bajo grado nuclear, subyacentemente hay nidos tumorales entre espacios vasculares que plantean diagnóstico diferencial entre papilas tumorales con el tallo conectivo vascular, y auténtico crecimiento infiltrante entre sinusoides.

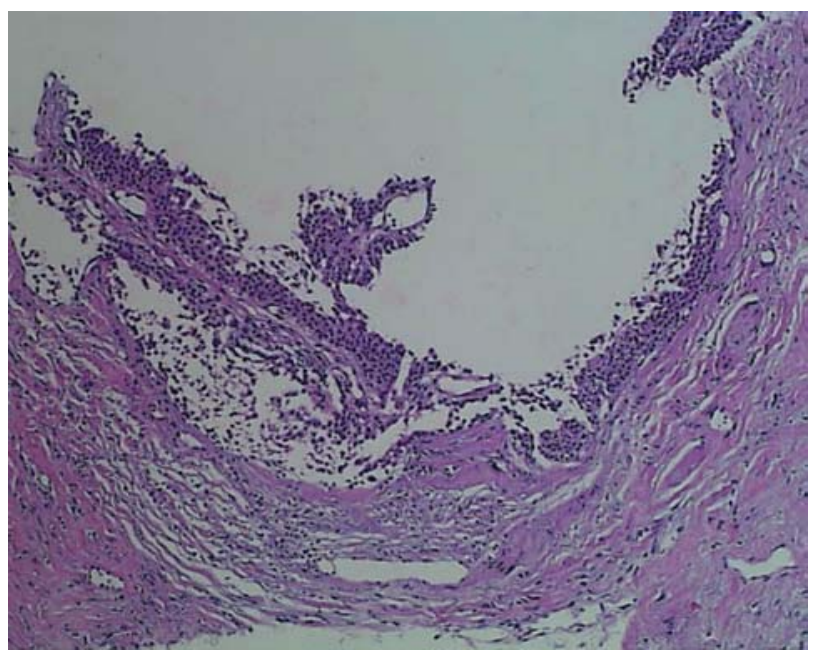

FIGURA 4. Nido tumoral de carcinoma transicional poco cohesivo inmerso en los cuerpos cavernosos, con un patrón de crecimiento invertido, con presencia de crecimientos papilares.

los 2 años del diagnóstico inicial. El priapismo metastático es con más frecuencia secundario a la afectación de los cuerpos cavernoso, seguida del glande y del cuerpo esponjoso ${ }^{1}$.

Clínicamente suele debutar con tumefacción peneana, en ocasiones dolorosa, dolor perineal, disuria, obstrucción urinaria, lesiones cutáneas secundarias a infiltración tumoral. La erección dolorosa aparece en el 30\% de las metástasis a pene secundarias a carcinoma vesical ${ }^{5}$. En raras ocasiones de produce retención aguda de orina secundaria a la afectación de la uretra y cuerpo esponjoso. También puede originar cuadros de hematuria y disuria ${ }^{1}$.

Debemos realizar diagnóstico diferencial con otros procesos que cursan con induración de los cuerpos cavernosos como priapismo idiopático, enfermedad de La Peyronie, trombosis del cuerpo cavernoso o de la arteria dorsal profunda, enfermedades venéreas o infecciosas, carcinoma primario del pene, etc. ${ }^{1,3,5-7}$.

Diferentes mecanismos han sido descritos para justificar la diseminación neoplásica que termina afectando a los cuerpos cavernosos, como la extensión por contigüidad, la diseminación linfática, la venosa retrógrada, la extensión arterial directa, el émbolo secundario y la instrumental ${ }^{6,8,9}$.

El diagnóstico debe efectuarse mediante biopsia de cuerpos cavernosos, confirmando finalmente el estudio anatomopatológico el origen tumoral $^{1}$. La ecografía puede demostrar en algunos casos la trombosis de los cuerpos cavernosos. Otras pruebas complementarias como la radiografía simple de tórax, la ecografía abdominal, la TAC y la gamma grafía ósea, son de utilidad para completar el estudio de diseminación, ya que la afectación sincrónica metastática de otros órganos es habitual.

Diferentes tratamientos se han planteado, como la amputación radical ó local se ha propuesto en pacientes con síntomas locales no controlables o lesión única metastática, la emasculación, radioterapia, quimioterapia, inmunoterapia y legrado de los cuerpos cavernosos ${ }^{6,7,8,10}$. Pero el mal pronóstico de estos pacientes falleciendo la mayoría en el primer año, justifica que el tratamiento de elección del priapismo metastático sea el paliativo ${ }^{1}$.

\section{CONCLUSIONES}

El priapismo metastático es una entidad clínica poco frecuente, aunque no excepcional en la práctica clínica urológica. Suele debutar en edades avanzadas y el tumor primario con más frecuencia asienta en el aparato genitourinario. El diagnóstico de presunción debe quedar confirmado mediante biopsia de los cuerpos cavernoso. 
En nuestro caso la afectación tumoral metastática en el momento del diagnóstico condicionó una actitud terapéutica paliativa.

\section{REFERENCIAS}

1. Robey E, Schellhammer P. Four cases of metastases to the penis and a review of the literature. J Urol 1984;132:992.

2. Ramos J, González J, Gómez V, Montero J. Priapismo como primera manifestación de un hipernefroma. Actas Urol Esp 1982;6:373-376

3. Cardoso G, Rodrigues R, Paiva Gadelha A et al. Penile metastasis of condrosarcoma of the jaw. Urology 2003 apr;61(4):837.

4. Marchal C, Contreras J, Chicharro JA et al. Enfermedad metastásica de pene. A propósito de tres casos. Actas Urol Esp 1993; 17: 461 .

5. Haddad F. Penile metastasis secondary to bladder cancer. Urol Int 1984;39:125.
6. Narayama A, Olney L, Howard D et al. Metastatic tumors of the penis. Eur Urol 1979;5:261.

7. Abeshouse B, Abeshouse G. Metastatic tumors of the penis: a review of the literature and report of two cases. J Urol 1961;86:99.

8. Trulock T, Wheatley J, Walton K. Secondary tumors of penis. Urology 1981;17:563.

9. Tannembau M. Transitional cell carcinoma of the prostate. Urology 1975;5:674.

10. Morga JP, Ferrero R, Guzmán PL et al. Metástasis priapism. Report of 4 new cases and review of the literatura. Arch Esp Urol 2000 jun;53(5):447-452.

Dr. M.Á. Trívez Boned

Avda. Pablo Ruiz Picasso, 52 - 2º D

50018 Zaragoza

(Trabajo recibido el 2 septiembre de 2003) 